\title{
Adhesion characteristics of geopolymer mortar to concrete and rebars
}

\author{
Sanjay PAREEK ${ }^{1, *}$, Hiroo Kashima ${ }^{1,2}$, Ippei Maruyama ${ }^{2}$ and Yoshikazu Araki ${ }^{2}$ \\ ${ }^{1}$ Department of Architecture, College of Engineering, Nihon University, Koriyama 963-8642, Japan \\ ${ }^{2}$ Department of Environmental Engineering and Architecture, Graduate School of Environmental Studies, Nagoya University, \\ Nagoya 464-8601, Japan
}

\begin{abstract}
In recent years, geopolymers have gained a wide attention as highly ecological-friendly building materials, having a capability to cut down $70 \%$ of $\mathrm{CO}_{2}$ emissions in comparison to the ordinary cement concrete. In this study, geopolymer mortars are proposed as repair materials for reinforced concrete structures, due to their superior acid resistance, heat resistance and high strength in comparison to the existing repair materials. The objective of this study is to investigate the adhesion properties of geopolymer mortars to concrete substrates with different surface treatments, steel plates and rebars. As a result, the geopolymer mortars are found to have excellent adhesion properties to dry concrete substrates, steel plates and rebars. Concrete substrates treated with grinder, further enhanced the adhesion properties of geopolymer mortars. On the other hand, poor adhesion of geopolymer mortars to wet concrete substrates was observed due to the presence of water on the interfacial zone, which decreased the alkali concentration of the geopolymer, resulting in lower adhesion strength. In general, geopolymer mortars are found to have suitable adhesion properties to the concrete substrates, steel plates and rebars and can be applied as repair materials for reinforced concrete structures.
\end{abstract}

\section{Introduction}

In order to build a sustainable society, it is highly important to facilitate long-term use of existing building stocks, in addition to reducing the consumption of natural resources and cutting down industrial waste production and $\mathrm{CO}_{2}$ emissions. For achieving this goal, it is necessary to develop eco-friendly materials for the repair and strengthening of reinforced concrete (RC) structures. Accordingly, there is a further need to develop new materials and technologies for $\mathrm{RC}$ structures in the construction industry.

The repair materials for $\mathrm{RC}$ structures are mainly classified into 3 categories: i) polymer/resin based materials; ii) polymer-cement based materials and; iii) cement based materials [1]. Mainly for RC structures, polymeric or polymer-cement based materials are used as repair materials, having poor heat, fire and acid resistance along with higher emissions of $\mathrm{CO}_{2}$ during the manufacturing and disposal process $[1,2]$.

In recent years, geopolymers (GP) have gained a wide attention as environmentally friendly building materials [3]. GP can utilize a large amount industrial waste such as fly ash (FA) as raw material and can help to cut down $\mathrm{CO}_{2}$ emissions up to $75 \%$ in comparison to ordinary cement concrete [4-6]. In addition, GP having high strength of $100 \mathrm{MPa}$, high acid and $\mathrm{Cl}^{-}$penetration resistance, superior refractory properties that cannot be attained by polymercement and ordinary cement concrete are reported [7-10]. The authors have been studying the strength characteristics and chemical resistance of GP and adhesion properties to steel plate, aiming for practical use of GP as building material [11-13]. In order to further expand the use of GP as repair material for RC structures, the adhesion characteristics of GP mortar to concrete substrates, steel plates and rebar need to be clarified. Until now, several studies have been conducted using GP as a repair material and are found to have excellent adhesion strength and durability in comparison to cement based repair materials [14-17]. Furthermore, Caroline et al. have pointed out that adhesion of GP to concrete substrate is greatly influenced by the surface treatment and showed higher adhesion strength to sand-blasted concrete

* Corresponding author: pareek@arch.ce.nihon-u.ac.jp 
substrates [18]. Momayez et al. have pointed out that treatment of concrete substrate by wire brush resulted in higher adhesion strength [19]. On the other hand, Caroline et al. showed that a decrease in adhesion strength is observed by treating the concrete substrate by grinder [18]. Eduardo et al. have reported an increase in adhesion strength by treating the concrete substrates by a grinder [20]. However, there is no research showing GP mortar under heat curing conditions and comparing the adhesion results for concrete substrates with various surface treatments, steel plates and rebar. Furthermore, there is no research report showing the influence of adhesion of GP mortar to old concrete substrates.

In this research work, adhesion properties of GP mortar to concrete substrates with various surface treatments, steel plates and rebar have been investigated by heat curing of bonded GP mortar. The GP mortars bonded to concrete substrates were tested for adhesion strength in tension and a scanning electron microscopy of the interfaces was conducted to clarify the adhesion mechanism. In addition, the bond strength of GP mortars to rebars by pull-out tests were conducted and the results were compared to previous research and the adhesion properties were clarified.

\section{Experimental program}

\subsection{Materials}

\subsubsection{GP mortar}

Table 1. shows the materials used to prepare GP mortar. The FA used is the type II ash specified in JIS A 62012008. Table 2. shows the chemical composition and physical property of FA, Quartz sand (water absorption rate: $0.28 \%$, particle size : $0.5 \mathrm{~mm}$ ) was used as fine aggregate material. An alkali activator, $7 \mathrm{M}$ sodium hydroxide solution (NA) and water glass $\left(\mathrm{SiO}_{2}: 35\right.$ to $38 \%$, $\mathrm{Na}_{2} \mathrm{O}: 17$ to $19 \%$, referred to as WG) mixed solution was used. Lignin sulfonic acid and polycarboxylic acid ether type high performance $\mathrm{AE}$ water reducing agent were used as admixture.

\subsubsection{Concrete}

Table 3 shows the materials used for making the concrete substrates. Ordinary Portland cement (referred to as OPC) specified in JIS R 5210-2009 was used for cement.
Table 1. Materials for geopolymer mortar.

\begin{tabular}{|c|c|c|c|}
\hline Materials & ID & Class & Density $\left(\mathrm{g} / \mathrm{cm}^{3}\right)$ \\
\hline Fly ash & FA & JIS Type II & 2.3 \\
\hline $\begin{array}{c}\text { Fine } \\
\text { aggregate }\end{array}$ & S & Silica sand (No.5) & 2.6 \\
\hline \multirow{2}{*}{$\begin{array}{l}\text { Alkaline } \\
\text { activator }\end{array}$} & WG & Water glass & 1.7 \\
\hline & NA & $7 \mathrm{M} \mathrm{NaOH}$ & 1.2 \\
\hline Admixture & Ad & - & - \\
\hline
\end{tabular}

Table 2. Chemical composition and physical property of fly ash.

\begin{tabular}{|c|c|c|c|c|c|c|}
\hline \multirow{2}{*}{$\begin{array}{c}\mathrm{SiO}_{2} \\
(\%)\end{array}$} & \multirow{2}{*}{$\begin{array}{c}\text { LOI } \\
(\%)\end{array}$} & \multirow{2}{*}{$\begin{array}{c}\text { Surface } \\
\text { area } \\
\left(\mathrm{cm}^{2} / \mathrm{g}\right)\end{array}$} & \multicolumn{3}{|c|}{ Active index } & Percent \\
\cline { 4 - 6 } & & & $7 \mathrm{~d}$ & $28 \mathrm{~d}$ & $91 \mathrm{~d}$ & $\begin{array}{c}\text { Flow } \\
(\%)\end{array}$ \\
\hline 65.3 & 2.0 & 3630 & 79 & 85 & 104 & 105 \\
\hline
\end{tabular}

Table 3. Materials for concrete.

\begin{tabular}{|c|c|c|c|}
\hline Materials & ID & $\begin{array}{c}\text { Density } \\
\left(\mathrm{g} / \mathrm{cm}^{3}\right)\end{array}$ & $\begin{array}{c}\text { Fineness modulus } \\
(\%)\end{array}$ \\
\hline OPC & $\mathrm{C}$ & 3.2 & - \\
\hline $\begin{array}{c}\text { Fine } * 1 \\
\text { aggregate }\end{array}$ & $\mathrm{S} 1$ & 2.6 & 2.8 \\
\cline { 2 - 4 } & $\mathrm{S} 2$ & 2.6 & 2.7 \\
\hline $\begin{array}{c}\text { Coarse } \\
\text { aggregate }\end{array}$ & $\mathrm{G}$ & 2.7 & 60 \\
\hline Admixture & $\mathrm{AE}$ & - & - \\
\hline
\end{tabular}

*1 Density in saturated surface dry condition

Table 4. Chemical composition and physical property of Portland cement.

\begin{tabular}{|c|c|c|c|c|c|}
\hline \multicolumn{2}{|c|}{$\begin{array}{c}\text { Chemical } \\
\text { compositions } \\
(\%)\end{array}$} & \multirow{2}{*}{$\begin{array}{c}\text { LOI } \\
(\%)\end{array}$} & $\begin{array}{c}\text { Surface area } \\
\left(\mathrm{cm}^{2} / \mathrm{g}\right)\end{array}$ & \multicolumn{2}{|c|}{\begin{tabular}{c} 
Compressive \\
strength \\
\cline { 5 - 6 }
\end{tabular}} \\
\cline { 1 - 3 } $\mathrm{MgO})$ & $\mathrm{SO}_{3}$ & & & $7 \mathrm{~d}$ & $28 \mathrm{~d}$ \\
\hline 1.5 & 2.1 & 2.2 & 3290 & 44.1 & 62.4 \\
\hline
\end{tabular}

Table 4. shows the properties of cement used. The fine aggregate used was crushed sand from Sukagawa-shi and Shirakawa-shi, Fukushima prefecture (Particle size : less than $5 \mathrm{~mm}$ in all), coarse aggregate used was crushed stone from Iwaki-shi, Fukushima prefecture (Particle size : 5 $20 \mathrm{~mm}$ ). The mixing water used for all mixes was tap water and a high performance polycarboxylic acid ether type $\mathrm{AE}$ water reducing agent was used.

\subsection{Mix proportions of GP mortar and concrete}

\subsubsection{GP mortar}

Table 5. shows the mix proportions of GP mortar. The mix proportions of GP mortar used for the preparation of specimens for bonding to concrete substrates, steel plates and rebar was obtained from several trial mixes with superior workability and strength test results. The ratio of WG to NA of GP used was 1.25 times and the ratio of alkali activator (WG + NA) to FA was 0.474 times. For 
mixing of GP mortar, a Hobart-type mixer was used. FA and fine aggregate were added and dry mixing was done for 180 seconds. Mixed solution in which an alkali activator and a high-performance $\mathrm{AE}$ water reducing agent were previously mixed was added and mixed for 420 seconds. The GP mortar after mixing and preparation of respective specimens was subjected to heat curing at $80^{\circ} \mathrm{C}$. The curing time was $3 \mathrm{~h}$ (compressive strength after heat curing $=17.0 \mathrm{~N} / \mathrm{mm}^{2}$ ) for the pull-out tests of the rebar. For the adhesion strength test in tension to concrete substrates and steel plates was set to $6 \mathrm{~h}$ (compressive strength after heat curing $=25.0 \mathrm{~N} / \mathrm{mm}^{2}$ ).

\subsubsection{Concrete}

In this paper, one of the objectives is to examine the adhesion properties of GP mortar using concrete substrate cured for long term. Therefore, concrete cured for two years after casting was used as substrates. The mix proportions of concrete are shown in Table 6. The concrete with a water-cement ratio of $57.9 \%$, a slump value of $18 \pm 2.5 \mathrm{~cm}$, and an air content of $4.5 \pm 1.5 \%$, was used for the preparation of substrates. Concrete substrate specimens of dimensions $100 \mathrm{~mm} \times 100 \mathrm{~mm} \times$ $400 \mathrm{~mm}$ were cast and subjected to $1 \mathrm{~d}$ moist cure $\left[20^{\circ} \mathrm{C}\right.$, $90 \%(\mathrm{RH})], 1 \mathrm{~d}$ hot water cure $\left(70^{\circ} \mathrm{C}\right)$ and $5 \mathrm{~d}$ dry cure

$\left[20^{\circ} \mathrm{C}, 60 \%(\mathrm{RH})\right]$ curing and stored at $20^{\circ} \mathrm{C}, 90 \%(\mathrm{RH})$

for two years before using as substrates for adhesion test.

\subsection{Surface treatment methods}

\subsubsection{Formwork steel plate and steel plate}

Surface treatments of formwork steel plate (SPF) and steel plate (SP) was done in accordance with JIS K 6848-1987. The surface was cleaned with n-hexane and abraded with No. 240 sand paper as specified in JIS R 6252-2006, and finally cleaned with acetone to remove all the dust particles.

\subsubsection{Concrete substrates}

Table 7. gives the details of surface treatment for concrete substrates. Based on the experimental results of Caroline et al. [18], Momayez et al. [19], Eduardo et al. [20], a preliminary experiment was carried out by wire brush and grinder treatment on the surface of concrete substrates
Table 5. Mix proportions of geoplymer mortar.

\begin{tabular}{|c|c|c|c|c|c|c|}
\hline WG/NA*1 & \multirow{2}{*}{$\begin{array}{c}\text { A/FA*2 } \\
(\%)\end{array}$} & \multicolumn{5}{|c|}{ Unit content $\left(\mathrm{kg} / \mathrm{m}^{3}\right)$} \\
\cline { 3 - 7 } & $(\%)$ & FA & S & WG & NA & AE \\
\hline 1.3 & 47.4 & 827 & 958 & 218 & 174 & 8.3 \\
\hline
\end{tabular}

*1 WG/NA : Water glass / 7M NaOH Ratio

$* 2 \mathrm{~A} / \mathrm{FA}$ : Alkaline activator (Water glass $+7 \mathrm{M} \mathrm{NaOH}$ ) / Fly ash ratio

Table 6. Mix proportion of concrete substrate.

\begin{tabular}{|c|c|c|c|c|c|c|}
\hline \multirow{2}{*}{$\begin{array}{c}\text { W/C } \\
(\%)\end{array}$} & \multicolumn{6}{|c|}{ Unit content $\left(\mathrm{kg} / \mathrm{m}^{3}\right)$} \\
\cline { 2 - 7 } & $\mathrm{C}$ & $\mathrm{W}$ & $\mathrm{S} 1$ & $\mathrm{~S} 2$ & $\mathrm{G}$ & $\mathrm{AE}$ \\
\hline 57.9 & 318 & 184 & 433 & 422 & 936 & 3.2 \\
\hline
\end{tabular}

Table 7. Condition of concrete substrates and surface treatment for geopolymer mortar bonding.

\begin{tabular}{|c|c|c|c|}
\hline ID*1 & Grinding & Pre-wetting*2 & $\begin{array}{c}\text { Alkaline activator } \\
\text { coating } * 3\end{array}$ \\
\hline DN & - & - & - \\
\hline DG & $\circ$ & - & - \\
\hline WN & - & 0 & - \\
\hline WG & $\circ$ & 0 & - \\
\hline WNA & - & 0 & 0 \\
\hline WGA & $\circ$ & 0 & 0 \\
\hline
\end{tabular}

*1 D : Specimen in dry condition. W : Specimen in pre-wetted condition. $\underline{\mathrm{N}}$ : No-treatment. $\mathrm{G}$ : Grinder treatment. A : Bonding surface coated with alkali activator.

*2 Concretes were immersed in water for $48 \mathrm{~h}$ before bonding geopolymer mortar

*3 Alkaline activator : Water glass $+7 \mathrm{M} \mathrm{NaOH}$

removing all fine residual particles by pressurized air and later wiping the surface by acetone. Adhesion strength test in tension between GP mortar and concrete was carried out As a result, grinder treatment showed a higher adhesion strength. Therefore, in this study, the surfaces of concrete substrates were treated by a grinder.

The wetting of concrete substrates surface before bonding GP mortars have controversial experimental results [18] and have not been clarified. Therefore, concrete substrates immersed in water for $48 \mathrm{~h}$ prior to bonding GP mortar and were tested for the influence of water on adhesion. Furthermore, to improve the adhesion of GP mortars to wet concrete substrates, an alkali activator (WG + NA) was coated on the bonding surface of concrete substrates. The coating amount of alkali activator was controlled by visual observation.

\subsection{Testing procedures}

\subsubsection{Pull-out test of rebars}

Fig. 1. shows the specimen dimension and test set-up of pull-out test. The test specimens were prepared in accordance with JCI-SPC 15 (Polymer cement mortar's 
adhesion strength test method (draft) for reinforced bars). Specimens were prepared by casting GP mortar which was mixed by the above-mentioned method into the molds $(150 \mathrm{~mm} \times 150 \mathrm{~mm} \times 150 \mathrm{~mm})$ in which rebars (D19SD345) were installed at the center, and subjected to heat curing after casting.

The tensile load and slip of the rebar at each loading interval was measured using displacement meter in accordance to JCI-SPC15. Three specimens were tested, and the bond stress was calculated from the measured maximum load by using eq. (1).

$$
\left\ulcorner_{b}=\frac{P_{\max }}{\varphi \cdot L}\right.
$$

Where :

$$
\begin{aligned}
\tau_{\mathrm{b}} & : \text { Bond strength }\left(\mathrm{N} / \mathrm{mm}^{2}\right) \\
L & : \text { Embeded length of rebar }(\mathrm{mm}) \\
P_{\max } & : \text { Load }(\mathrm{N}) \\
\Phi & : \text { Perimeter of rebar }(\mathrm{mm})
\end{aligned}
$$

\subsubsection{Adhesion strength test in tension of GP mortar to concrete and steel plate}

Fig. 2. shows the specimen dimensions and test set-up for adhesion strength test in tension. The formwork (10 $\mathrm{mm} \mathrm{x}$ $100 \mathrm{~mm}$ x $400 \mathrm{~mm}$ ) was fixed to surface treated concrete substrates, formwork steel plate and steel plate respectively, with a bonding tape. The test specimens were prepared by casting the GP mortar which was kneaded by the above-mentioned method and subjected to heat curing at $80^{\circ} \mathrm{C}$ for $6 \mathrm{~h}$.

After heating curing and cooling to room temperature, the formwork of specimens were carefully removed and cut to $40 \mathrm{~mm} \times 40 \mathrm{~mm} \times 15 \mathrm{~mm}$ depth and $40 \mathrm{~mm} \times 40 \mathrm{~mm} \times$ $10 \mathrm{~mm}$ for the concrete substrates and steel plates respectively, with a concrete cutter. An epoxy adhesive was applied to the surface of the test pieces, and a steel jig was bonded for testing the adhesion strength. The test specimens were left in a thermostatic chamber until the adhesive was completely cured.

Fig. 2. shows the dimensions and test set-up for adhesion strength test in tension. The cured specimens were tested for adhesion in tension using a manually operated pullgage in accordance with JIS A 6915 (Wall coatings for thick textured finishes). The adhesion strength in tension

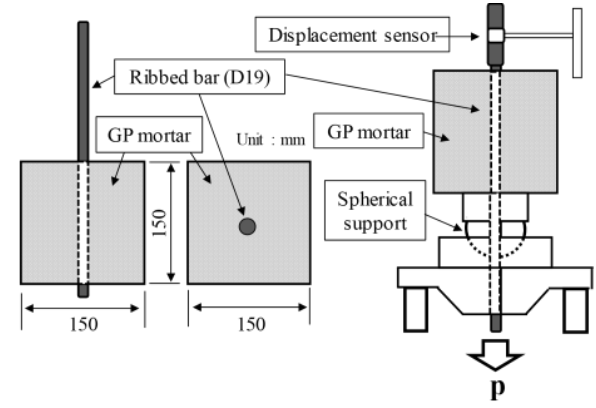

Fig. 1. Specimen dimension and test set-up of pull-out test of rebar.

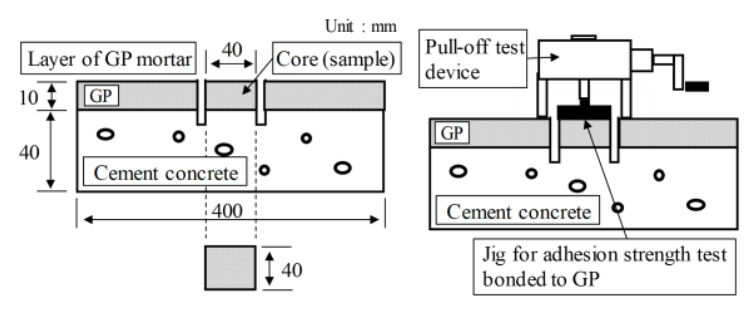

Fig. 2. Specimen dimension and test set-up of adhesion in tension test.

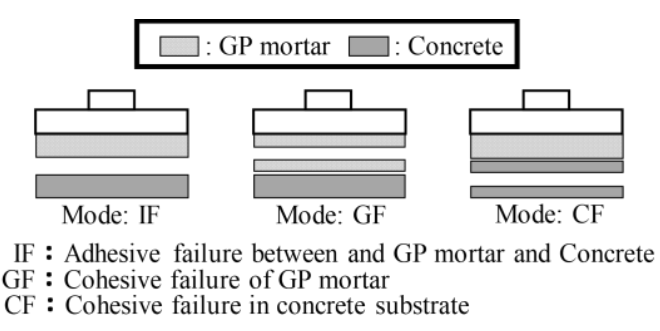

Fig. 3. Failure modes of specimens in adhesion in tension test.

$$
\sigma_{a}=\frac{P}{A}
$$

Where:

$$
\begin{aligned}
\sigma_{\mathrm{a}} & : \text { Adhesion in tension }\left(\mathrm{N} / \mathrm{mm}^{2}\right) \\
A & : \text { Cross-sectional area of honded surface }\left(\mathrm{mm}^{2}\right) \\
P & : \operatorname{Load}(\mathrm{N})
\end{aligned}
$$

was an average of 3 specimens and calculated as in eq. (2). Fig. 3. represents the type of failure modes of specimen. After adhesion test, the failed cross-sections of the specimens were observed for failure modes, which were basically classified into the following three types: [IF] adhesive failure at the interface; $[\mathrm{GF}]$ Cohesive failure in the bonded GP mortar; [CF] Cohesive failure in concrete substrate. 


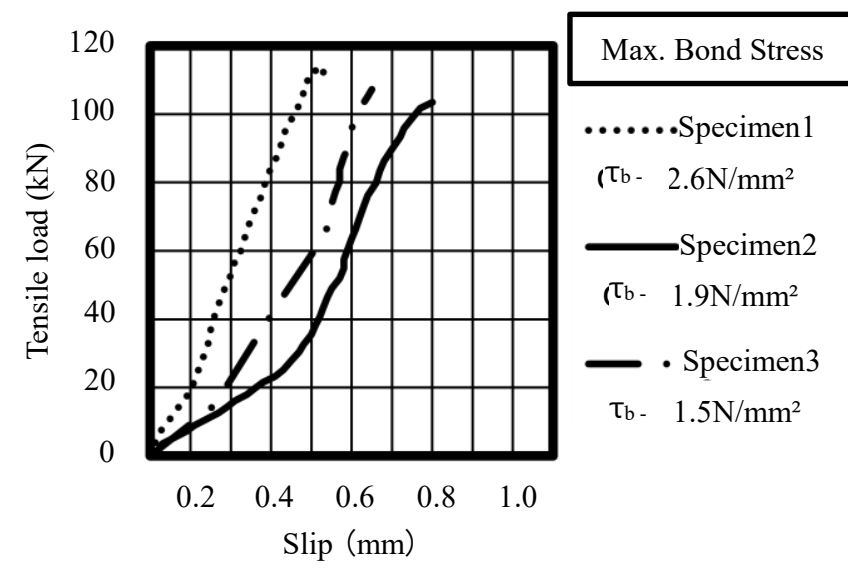

Fig. 4. Tensile load - slip curves by pull-out test of rebar embedded in geopolymer mortar.

\subsubsection{Microstructure analysis of adhesion interface}

The microstructure analysis of adhesion interface between the concrete substrate and the bonded GP mortar was observed using a field emission scanning electron microscope (FE-SEM).

\section{Test results and discussion}

\subsection{Pull-out test of rebars}

Fig. 4. shows tensile load-slip curve of the rebar embedded in GP mortar and maximum bond stress. The bond stress was the highest for Specimen 1 which showed $12.6 \mathrm{~N} / \mathrm{mm}^{2}$, and the lowest for Specimen 3 with 11.5 $\mathrm{N} / \mathrm{mm}^{2}$. In all specimens, the maximum bond stress tends to decrease with increasing slip.

Ota et al. investigated the adhesion properties of GP mortar and rebars, and found out cement mortar was 7.1 $\mathrm{N} / \mathrm{mm}^{2}$ when using deformed rebars, while the GP mortar had a maximum bond stress of $14.8 \mathrm{~N} / \mathrm{mm}^{2}$ and showed higher bond stress in comparison to cement mortar [21]. Ota et al. also stated that GP mortar also has better bond properties than cement mortar in plain round steel bars [21]. Yifei et al. also reported that GP concrete had better bond stress than cement concrete when deformed rebars were used and reported that adhesion strength improved by fiber reinforcement of concrete [17]. On the other hand, Arnaud et al. reported an improvement of bond stress of GP concrete by about $10 \%$ in comparison to ordinary concrete when using deformed rebars. However, when using plain round steel bars, the bond stress was higher in ordinary concrete [22]. Minami reported that the

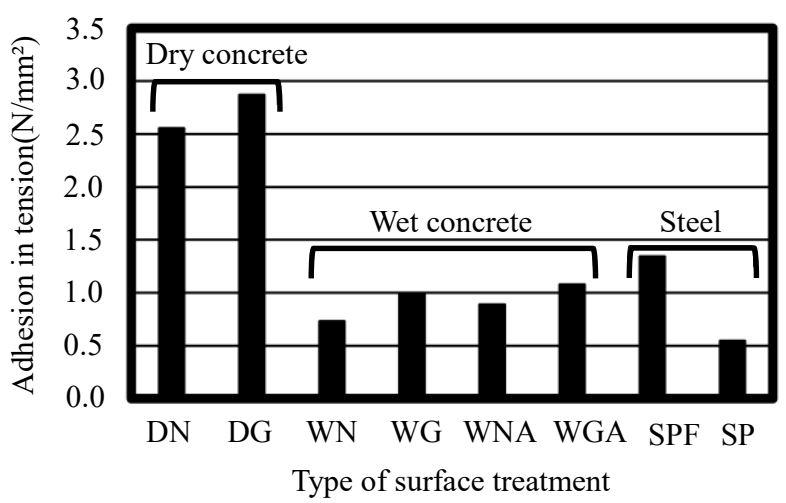

Fig. 5. Adhesion strength in tension between geopolymer mortar and concrete substrate with different surface treatment and steel plates. D: Specimen in dry condition. W: Specimen in pre-wetted condition. N: No-treatment. G: Grinder treatment. A: Bonding surface coated with alkali activator.

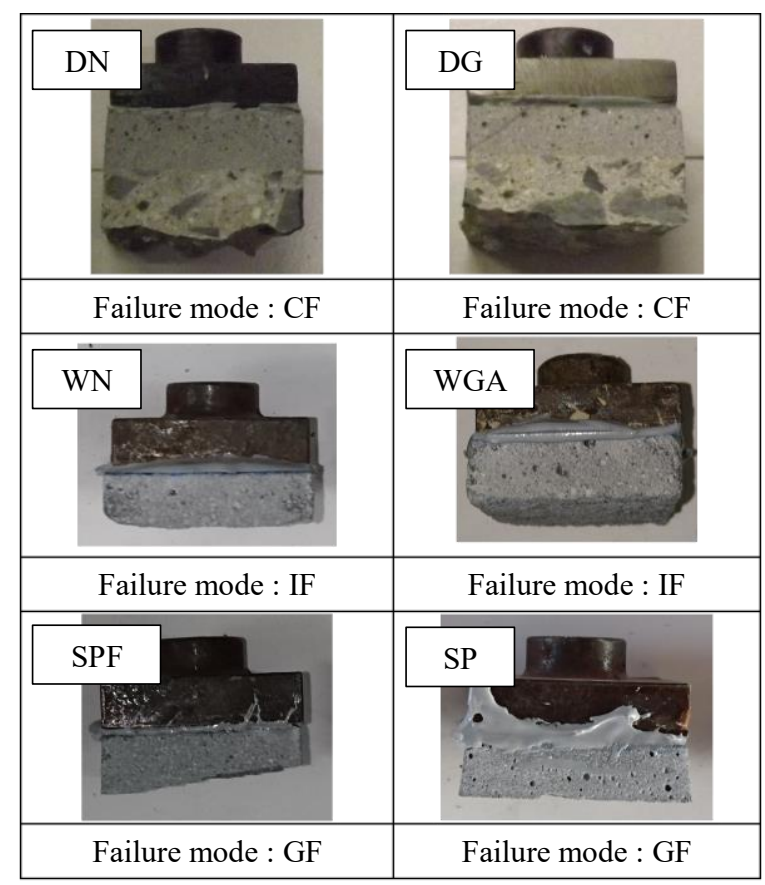

Fig. 6. A view of failure modes of specimens after adhesion strength tests.

maximum adhesion strength of ordinary concrete and GP concrete is almost equal when using plain round rebars [23].

From the above references, there is no unified view on the bond stress between GP and different types of rebars at present. In order to clarify the adhesion characteristics, it is necessary to conduct a unified test by changing the type of rebars, mix-proportions of GP, curing conditions etc. For example, Silva et al. [24] have reported experimental results by chaining the composition of GP. Nagatomo et al. [25] have taken into consideration the influence of a single 


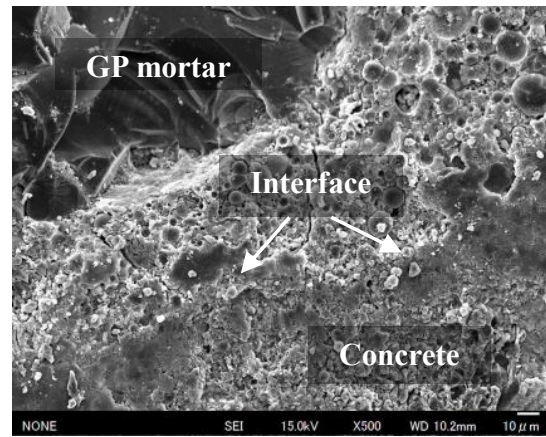

(1) Dry-Grinder (DG)

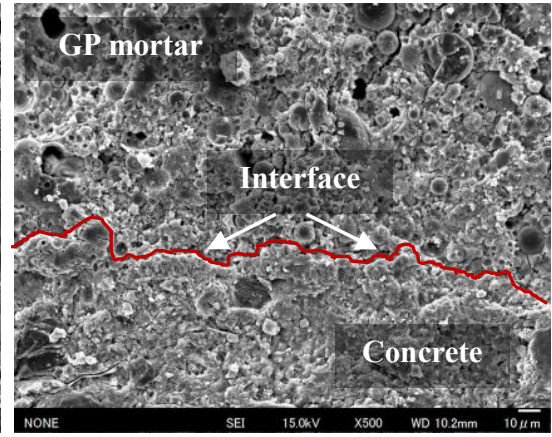

(2) Dry-No treatment (DN)

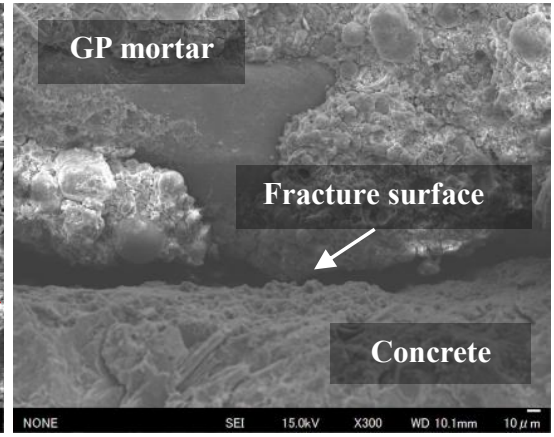

(3) Wet-Grinder-A-coating (WGA)

Fig. 7. SEM micrographs of interfacial transition zone between geopolymer mortar and concrete substrates.

transverse rib, rib angle, rib height, the distance from loading end to the rib and compressive strength properties of concrete on bond stress of rebars.

\subsection{Adhesion strength test of GP mortar to concrete and steel plates}

Fig. 5. illustrates the adhesion strength test results of GP mortars to concrete substrates, form steel plates (SPF) and steel plates (SP). For concrete substrates, the adhesion strength was the highest for DG that showed $2.86 \mathrm{~N} / \mathrm{mm}^{2}$ and $\mathrm{WN}$ indicated $0.73 \mathrm{~N} / \mathrm{mm}^{2}$ which was the lowest value. For all specimens using concrete substrates, the adhesion strength improved by applying a grinder treatment to the bonding surface. For steel plates, the adhesion strength of SPF was particularly high at 1.34 $\mathrm{N} / \mathrm{mm}^{2}$. Momayez et al. conducted adhesion strength test for concrete with different surface condition and bonded by cement based repair material, and reported that the adhesion strength was $1.32 \mathrm{~N} / \mathrm{mm}^{2}$ [19]. In addition, Eduardo et al. conducted a tensile bond strength test between concrete substrates with different surface treatments and bonded by new concrete. In particular, it was reported that highest adhesion strength $2.65 \mathrm{MPa}$ was achieved by sandblasting treatment [20]. The composition of the base material, the method of surface treatment and the dimensions of the test specimen used in this paper are different from the above-mentioned reports, so a strict comparison can not be made. However, most of the previous researches, the test method is the same as to this research, and it can be said that the adhesion strength has a correlation. The adhesion strength of GP obtained in this study was a maximum of $2.86 \mathrm{~N} / \mathrm{mm}^{2}$, which was the highest when compared to the results of adhesion strength in the research report of Momayez et al. [19], Eduardo et al. [20]. From the above points, it can be stated that GP mortar has excellent adhesion to concrete substrates, satisfying one of the major requirements of repair material for RC structures.

Fig. 6. shows the failure modes of specimens after adhesion strength test. For both DN and DG with high adhesion strength, cohesive failure of concrete substrate occurred, and in both SP and SPF, cohesive failure of bonded GP occurred. On the other hand, in the $\mathrm{W}$ series, an adhesive failure at the interface of bonded GP mortar and concrete was observed showing poor adhesion.

\subsection{SEM observation of adhesion interface}

Fig. 7. shows SEM micrographs of interfacial transition zone between bonded GP mortar and concrete substrates with different surface conditions. DG which showed the highest adhesion strength, the interfacial transition zone between GP mortar and concrete can not be clearly confirmed. DN with high adhesion strength shows similar bonding at interfacial zone between GP and concrete like DG. On the other hand, it can be confirmed that the WGA shows a distinct interfacial zone with some gaps on the adhesion interface between GP mortar and concrete substrate with poor adhesion. This is because of the presence of large amount of water on the bonding surface of the concrete substrate. The presence of large amount of water at the interfacial zone between the GP and concrete substrate lowers the alkali concentration of GP mortar. As a result, it leads to decrease in adhesion strength and an adhesive failure mode at interfacial zone was observed. The reason for higher adhesion strength of DN and DG in comparison to $\mathrm{W}$ series is reported by Zhang et al. and Tanakorn et al., and is due to $\mathrm{Si}^{4+}$ and $\mathrm{Al}^{3+}$ contained in GP mortar reacted with $\mathrm{Ca}(\mathrm{OH})_{2}$ on the concrete surface layer 
and an increase in calcium silicate hydrate $\mathrm{CSH}$ and CASH gel), resulting in a dense interface which is of high strength [16] [26]. Also in this paper, Zhang et al.and Tanakorn et al., reported DN and DG showed high adhesion strength because of CSH and CASH gel that was formed at the interfacial transition zone between GP mortar and concrete substrate.

\section{Conclusions}

In this paper, the proposed GP mortar as repair material for RC structures have been tested for adhesion properties to concrete substrates, formwork steel plates, steel plates and rebars and the following conclusion can be derived as below.

1) In general, GP mortar as repair material for $\mathrm{RC}$ structures has a good adhesion strength to dry concrete substrates, formwork steel plates and rebars. The adhesion strength of GP mortar to concrete was further enhanced by treating the concrete substrate bonding surfaces with a grinder.

2) GP mortar demonstrated poor adhesion strength to wet concrete substrates. Due to the presence of large amount of water at bonding surface of concrete substrates, the alkali concentration of bonding GP mortar was lowered at the interface leading to poor adhesion.

This work was supported by JSPS KAKENHI Grant-in-Aid for Scientific Research A, (Grant number: 16H02376, Lead researcher : Yoshikazu Araki).

\section{References}

1. D. R. Morgan, Compatibility of concrete repair materials and systems, Construction and Building Materials, 10, 57-67, (1996)

2. Tianming Gao, Lei Shen, Ming Shen, Litao Liu, Fengnan Chen, Analysis of material flow and consumption in cement production, Journal of Cleaner Production, 112, 553-556, (2016)

3. J. Davidovits, GEOPOLYMERS Inorganic polymeric new materials, Journal of Thermal Analysis, 37, 1633-1656, (1991)

4. Xiaolu Guo, Huisheng Shi, Warren A. Dick, Compressive strength and microstructural characteristics of class C fly ash geopolymer,
Cement \& Concrete Composites, 32, 142-147, (2010)

5. Jae Eun Oh, Paulo J. M. Monteiro, Ssang Sun Jun, Sejin Choi, Simon M. Clark, The evolution of strength and crystalline phases for alkaliactivated ground blast furnace slag and fly ashbased geopolymers, Cement and Concrete Research, 40, 189-196, (2010)

6. Keun-Hyeok Yang, Jin-Kyu Song, Keum-1l Song, Assessment of $\mathrm{CO}_{2}$ reduction of alkaliactivated concrete, Journal of Cleaner Production, 39, 265-272, (2013)

7. A. Fernandez-Jimenez, I. Garcia-Lodeiro, A. Palomo, Durability of alkali-activated fly ash cementitious materials, Journal of Materials Science, 42, 3055-3065, (2007)

8. T. Bakharev, Resistance of geopolymer materials to acid attack, Cement and Concrete Research, 35, 658-670, (2005)

9. T. W. Cheng, J. P. Chiu, Fire-resistant geopolymer produced by granulated blast furnace slag, Minerals Engineering, 16, 205-210, (2003)

10. Zuhua Zhang, Xiao Yao, Huajun Zhu, Potential application of geopolymers as protection coatings for marine concrete II. Microstructure and anticorrosion mechanism, Applied Clay Science, 49, 7-12, (2010)

11. Yuta Igarashi, Sanjay PAREEK, Effects of Slag Replacement Ratio and Curing Condition on the Compressive Strength of Geopolymer Mortars Using Fly Ash from India and Japan, Proceedings of the Japan Concrete Institute (Japanese), 37, 1885-1890, (2015)

12. Yuta Igarashi, Sanjay PAREEK, Resistance to high concentration of hydrochloric acid solution by geopolymer mortars using fly ash and electric arc furnace slag, Proceedings of the Japan Concrete Institute (Japanese), 38, 2319-2324, (2016)

13. Hiroo Kashima, Sanjay PAREEK, Ippei Maruyama, Yoshikazu Araki, Effect of releasing agent on debonding behavior between geopolymer mortar and steel plate, Proceedings of the Japan Concrete Institute (Japanese), 39, 1351-1356, (2017) 
14. Fernando Pacheco-Torgal, J. P. Castro-Gomes, Said Jalali, Adhesion characterization of tungsten mine waste geopolymeric binder. Influence of OPC concrete substrate surface treatment, Construction and Building Materials, 22, 154-161, (2008)

15. Smith Songpiriyakij, Tawich Pulngern, Pompong Pungpremtrakul, Chai Jaturapitakkul, Anchorage of steel bars in concrete by geopolymer paste, Materials and Design, 32, 3021-3028, (2011)

16. Tanakorn Phoo-ngernkham, Vanchai Sata, Sakonwan Hanjitsuwan, Charoenchai Ridtirud, Shigemitsu Hatanaka, Prinya Chindaprasirt, High calcium fly ash geopolymer mortar containing Portland cement for use as repair materials, Construction and Building Materials, 98, 482-488, (2015)

17. Yifei Cui, Obada Kayali, Tiejun Zhao and Chunwei Zhang, Bond Strength of Steel Bar and Plain of Fiber Reinforced Geopolymer Concrete, The 2017 World Congress on Advances in Structure Engineering and mechanics (ASEM17), (2017)

18. Caroline Talbot, Michel Pigeon, Denis Beaupre and D. R. Morgan, Influence of Surface Preparation on Long-Term Bonding of Shotcrete, ACI Materials Journal, 91, 560-566, (1994)

19. A. Momayez, M. R. Ehsani, A. A. Ramezanianpour, H. Rajaie, Comparison of methods for evaluating bond strength between concrete substrate and repair materials, Cement and Concrete Research, 35, 748-757, (2005)
20. Eduardo N. B. S. Julio, Fernando A. B. Branco, Vitor D. Silva, Concrete-to-concrete bond strength. Influence of the roughness of the substrate surface, Construction and Building Materials, 18, 675-681, (2004)

21. Shu Ota, Yasutake Sagawa, Koji Harada, Takeyoshi Nishizaki, A fundamental study on bond strength properties of geopolymer mortar, Proceedings of the Japan Concrete Institute (Japanese), 38, 2313-2318, (2016)

22. Arnaud Castel, Stephen J. Foster, Bond strength between blended slag and Class F fly ash geopolymer concrete with steel reinforcement, Cement and Concrete Research, 72, 48-53, (2015)

23. Kosuke Minami, Taku Matsubayashi, Hideyuki Kajita, Takatsune Sato, Study on Structural Use for Geopolymer Concrete, Proceeding of JCI Symposium on Current Status and Issues of Geopolymer Technology in the Construction Sector (Japanese), 99-102, (2016)

24. Pre De Silva, Kwesi Sagoe-Crenstil, Mediumterm phase stability of $\mathrm{Na}_{2} \mathrm{O}-\mathrm{Al}_{2} \mathrm{O}_{3}-\mathrm{SiO}_{2}-\mathrm{H}_{2} \mathrm{O}$ geopolymer systems, Cement and Concrete Research, 38, 870-876, (2008)

25. Katsuhiro NAGATOMO, Tetsuzo KAKU, Study on bond characteristics of deformed bars with only a single transverse rib, Japan Society of Civil Engineers (Japanese), 372, 177-186, (1986)

26. Zuhua Zhang, Xiao Yao, Huajun Zhu, Potential application of geopolymers as protection coatings for marine concrete 1. Basic properties, Applied Clay Science, 49, 1-6, (2010) 